\title{
Office Hours Re-imagined: Mentored Learning in Ideation Spaces
}

\author{
Dr. Thomas F. Schubert Jr. P.E., University of San Diego
}

Thomas F. Schubert, Jr. received his B.S., M.S., and Ph.D. degrees in electrical engineering from the University of California, Irvine. He is currently a Professor of electrical engineering at the University of San Diego, San Diego, CA and came there as a founding member of the engineering faculty in 1987 . He previously served on the electrical engineering faculty at the University of Portland, and Portland State University, and on the engineering staff at Hughes Aircraft Company. Prof. Schubert is a member of ASEE and IEEE and is a registered professional engineer in Oregon. He is the 2012 winner of the ASEE Robert G. Quinn award for excellence in engineering education.

\section{Prof. Frank G. Jacobitz, University of San Diego}

Frank G. Jacobitz was born in Göttingen, Germany, in 1968. He received the Diploma in physics from Georg-August Universität, Göttingen, Germany, in 1993, and the M.S. and Ph.D. degrees in mechanical engineering from the University of California, San Diego, La Jolla, in 1995 and 1998, respectively. He has been with the University of San Diego, San Diego, CA, since 2003, where he is currently a Professor of mechanical engineering. From 1998 to 2003, he was an Assistant Professor of mechanical engineering with the University of California, Riverside. He has also been a visitor with the Centre National de la Recherche Scientifique at Aix-Marseille Université in Marseille, France. His research interests include direct numerical simulations of turbulent flows with shear, rotation, and stratification, as well as biofluid mechanical problems at the microscale. Prof. Jacobitz is a Member of the American Society of Mechanical Engineers (ASME), the American Association for the Advancement of Science (AAAS), the American Physical Society (APS), the European Mechanics Society (EUROMECH), and the Deutsche Physikalische Gesellschaft (DPG). He currently serves as the faculty advisor to the student section of the ASME at the University of San Diego and the President of the Pacific Division of the AAAS. He received the Outstanding Engineering Educator Award from the San Diego County Engineering Council in 2008, the Faculty of the Year Award from the Zeta Omega Chapter of Beta Theta Pi Fraternity in 2013, the Outstanding Undergraduate Research Mentor Award from the University of San Diego in 2014, the Preceptor Award of the University of San Diego in 2015, and Best Paper Awards from the Division of Experimentation and Laboratory Oriented Studies of the American Society for Engineering Education in 2008 and 2014.

\section{Dr. Ernest M. Kim, University of San Diego}

Ernie Kim received his BSEE from the University of Hawaii at Manoa, and MSEE and PhD in Electrical Engineering from New Mexico State University. He has been an electronics engineer at the National Bureau of Standards (now NIST) at the Boulder CO labs where he performed research on precision optical fiber metrology, staff engineer with the Advanced Systems Group of Burroughs Corporation, Manager of Electro-Optics at Ipitek Corporation where he developed early fiber optic CATV systems. Dr. Kim has worked at a number of start-up companies in fiber optic transmission including All Optical Networks, and Lightwave Solutions in San Diego. He joined the University of San Diego Department of Electrical Engineering in 1990. Dr. Kim is a licensed Professional Engineer (EE), and regularly teaches FE and PE exam review courses. 


\title{
Office Hours Re-imagined: Mentored Learning in Ideation Spaces
}

\begin{abstract}
Student visitation during traditional office hours are an important component in student learning. However, they are limited as to student throughput due not only to time limitations but also physical space. Physical space limitation acts as a bottleneck to both faculty-student and studentstudent interaction and mentoring. In September 2015, the University opened an ideation space with reconfigurable walls, abundant board space, computer monitors and projectors, as well as roaming tables and chairs. The space was quickly adopted by students learning in groups or individually. A group of faculty from two engineering disciplines decided to hold about half of their scheduled office hours in the ideation space. It quickly became obvious that the new ideation space allows for a different interaction with students seeking help. The available space allows for multiple groups of students to interact with each other as well as interact with the faculty mentor concurrently. Initial student feedback indicates that the students generally prefer ideation space mentoring and find it a more effective learning experience. Efficacy comparisons to traditional office hour mentoring covering a one-semester deployment are made in this paper. Additional survey results and data on ideation space utilization as compared to traditional office hours covering a full academic year will be presented at the conference.
\end{abstract}

\section{Introduction}

Student visitation with faculty during scheduled office hours is an important aspect of the learning experience. In addition, such visitation has been shown to positively affect student motivation and academic self-confidence ${ }^{[1]}$ as well as an increased sense of purpose ${ }^{[2]}$. Many students feel that encouragement by faculty during office hours helped build the students' confidence, and, after meeting with professors during office hours, felt more comfortable asking questions during classroom time ${ }^{[3]}$. Nadler and Nadler ${ }^{[4]}$ conclude that "Education does not stop at the classroom doors and neither should our scholarly exploration of communication in this environment." While much of the current literature is focused on virtual office hours ${ }^{[5]}$, traditional one-on-one, face-to-face office hours still play an important part in student success.

Office hours held in a private, faculty office provide many positive aspects. As one student recently reported on the survey for this current study "[the] Office [is] good for more private meetings and one-on-one advising. " Unfortunately, student-faculty meeting held in a typical faculty office can also present obstacles to overcome: another student in this study reported "[the faculty office has] more privacy but for this course a lot of students have questions so the office was full every office hour." While traditional office hours and virtual office hours are the most common alternatives, it seems reasonable to investigate other possibilities.

In fall, 2015, The Shiley-Marcos School of Engineering (SMSE) at the University of San Diego (USD) added an ideation space in support of engineering design activities and education (with support from Cymer, Inc.). This $1600 \mathrm{ft}^{2}$ open, reconfigurable idea center provides a seating area, teleconferencing facilities, flexible furniture and a mobile panel grid system with writable 
white boards, all designed to encourage collaboration and exploration. The space was quickly adopted by students for a variety of activities, ranging from leisurely activities between classes, to group study work, to design project meetings. Three of the SMSE engineering faculty decided to hold a portion of their office hours in this ideation space with the goal of transforming traditional office hours into project-based, group learning experiences.

Ideation refers to the formation of ideas from their initial creative generation, through their development, to their application or communication. Hence ideation is an important component of the engineering design process ${ }^{[6]}$. However, ideation concepts have been applied in a variety of areas, including economics and sociology ${ }^{[7]}$.

Ideation concepts are introduced to engineering students in the context of alternative design generation. Examples for intuitive methods are brainstorming, Osborne's checklist, or random stimulation ${ }^{[8]}[9]$. On the other hand, logical methods are database-oriented ${ }^{[10][11]}$. Shah, Smith, and Vargas-Hernandez ${ }^{[12]}$ developed assessment measures to assess ideation effectiveness. Their outcome-based metrics are based on quantity, quality, novelty, and variety.

This paper is a first evaluation of this novel approach to office hours. The intent of this first study is to evaluate student preferences concerning receiving faculty assistance in the areas of homework, additional examples, questions about the lectures, preparation for examinations, and academic advising.

\section{Use of the ideation space}

Each of the three faculty involved divided the USD requirement for at least five weekly office hours between the faculty office and the SMSE ideation space:

- One faculty member divided the weekly office hours into two hours held in the faculty office and three hours held in the ideation space. During the first week of classes, it was assured that all students are able to attend at least one hour per week.

- Another faculty member held three weekly office hours in the faculty office and, similarly, three hours in the ideation space. During the first week of classes, students voted on office hour timing with the intent of servicing as many students as possible in each space. Two hours dedicated to each space were at the same time (early afternoon on Monday for the ideation space and on Wednesday for the faculty office).

- The third faculty member held office hours in a faculty office on Monday and Wednesday for 2 hours per day and used the ideation space for one and one-half hours in the mornings of Tuesday and Thursday.

As a comparison, the faculty offices in SMSE are typically approximately $120 \mathrm{ft}^{2}$ with a few larger offices of approximately $165 \mathrm{ft}^{2}$. The smaller offices typically have 2 or 3 side chairs for students while the larger offices can accommodate 3 to 5 chairs for students. Two of the faculty members involved in this study have the smaller offices with one study member having a larger office.

\section{Courses involved in this study}


The courses involved in this study are those assigned to the authors based on departmental needs. As such these courses span the range of engineering course offerings at SMSE from introductory freshman courses to senior-level courses:

- ENGR 101H: The honors section of Introduction to Engineering meets twice a week for two hours of lectures and labs. The course is focused on the design of a hill-climbing vehicle, which is designed using SolidWorks, built using laser-cut plywood, and controlled by an Arduino controller. The course topics include an introduction to the engineering design process, engineering drawings and SolidWorks, basic shop practices and safety, programming and Arduino controllers, and engineering analysis in Excel. Sixteen incoming first-year students were enrolled in this course.

- MENG 300: Two sections of this junior-level mechanical engineering thermodynamics course were part of this study. The course covers thermodynamic cycles (Rankine, Otto, Diesel, and Brayton cycles), psychrometrics, and thermodynamic relations and analysis. Each section had an enrollment of about twenty students.

- ENGR 311 is a traditional introductory junior-level materials science course with an emphasis at the end of the semester on electrical properties of materials. This course had and enrollment of thirty-five students.

- ELEC 470: The single section of this senior-level electrical engineering course in communication systems was part of this study. The course and its associated laboratory cover: signal analysis, analog and digital modulation and detection techniques, modern communication circuits and devices, along with applications of probability theory and random processes to communication systems. There were twenty-nine students enrolled in the course.

- ENGR 296/MENG 496: The ideation space was also used for weekly undergraduate research meetings to discuss progress and directions of the research project. There were ten students participating in these research project courses.

\section{The student survey instrument and results}

The students participating in this study were each given a simple survey consisting of nine questions and two spaces for general commentary. The first two questions asked which course applied to the study and whether that course fulfilled a general engineering breadth requirement or was required for the major. The next two questions asked about frequency of attending office hours and whether the student attended office hours in the ideation space. The five primary questions for this survey asked, on a seven point Likert scale, about preference between having office hours in faculty offices as opposed to the ideation space in five general categories: help with homework, examples, exam preparation, questions from the lecture, and academic advising (Figure 1). The two final spaces asked for "comment on the relative usefulness of office hours in the ideation space and the professor's office" and "other comments concerning using the ideation space." 
For the following questions, please indicate by checking one box for each question, which office hour location you preferred when seeking:

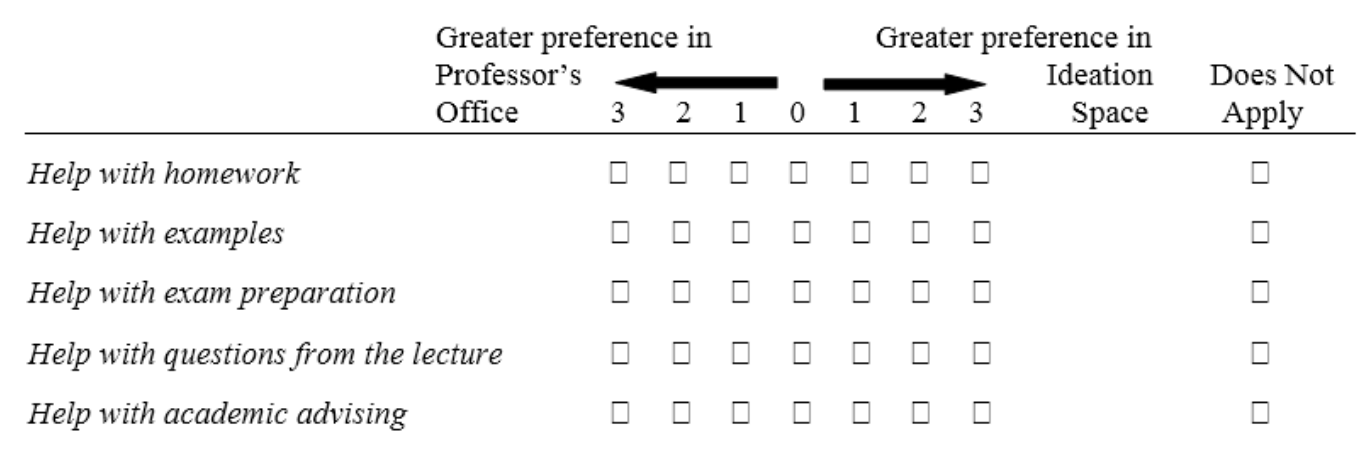

Figure 1 Survey preference questions.

While students were encouraged to respond, completion of the survey forms was not a requirement in any of the classes and all student responses were anonymous. A total of 68 students completed survey forms. Of that number, 16\% responded "I don't attend office hours", $54 \%$ reported attending office hours "some weeks", $21 \%$ reported attending weekly, and 9\% multiple times a week with a mean value of 1.9 times a week. $62 \%$ reported attending office hours in the ideation space.

In response to the five preference questions, students preferred the ideation space for three of the queried activities, had no real preference for one activity, and strongly preferred traditional office hours in the faculty office for one of the queried activities.

Students clearly preferred receiving faculty assistance concerning help with examples (Figure 2) and exam preparation (Figure 3 ) in the ideation space. Each showed an average of just over one full step (examples: 1.13 - exam preparation: 1.08). The ideation space was also preferred for help with homework assignments (Figure 4), but not quite as strongly (0.62 steps). Interestingly, the preference for the ideation space in these three categories was stronger by 0.18 to 0.81 steps among the students of faculty with smaller offices (homework: 1.42 - examples: 1.31 - exam preparation 1.52). It is not clear at this point if faculty office size is a contributing factor in student preferences.

Student preferring the ideation space for these topics provided positive commentary:

- "I.S. [ideation space] great for review sessions for tests - F.O. [faculty office] great for more personal help/questions"

- "there wasn't an issue of having enough space"

- "professor was able to help more people at once in ideation space" 


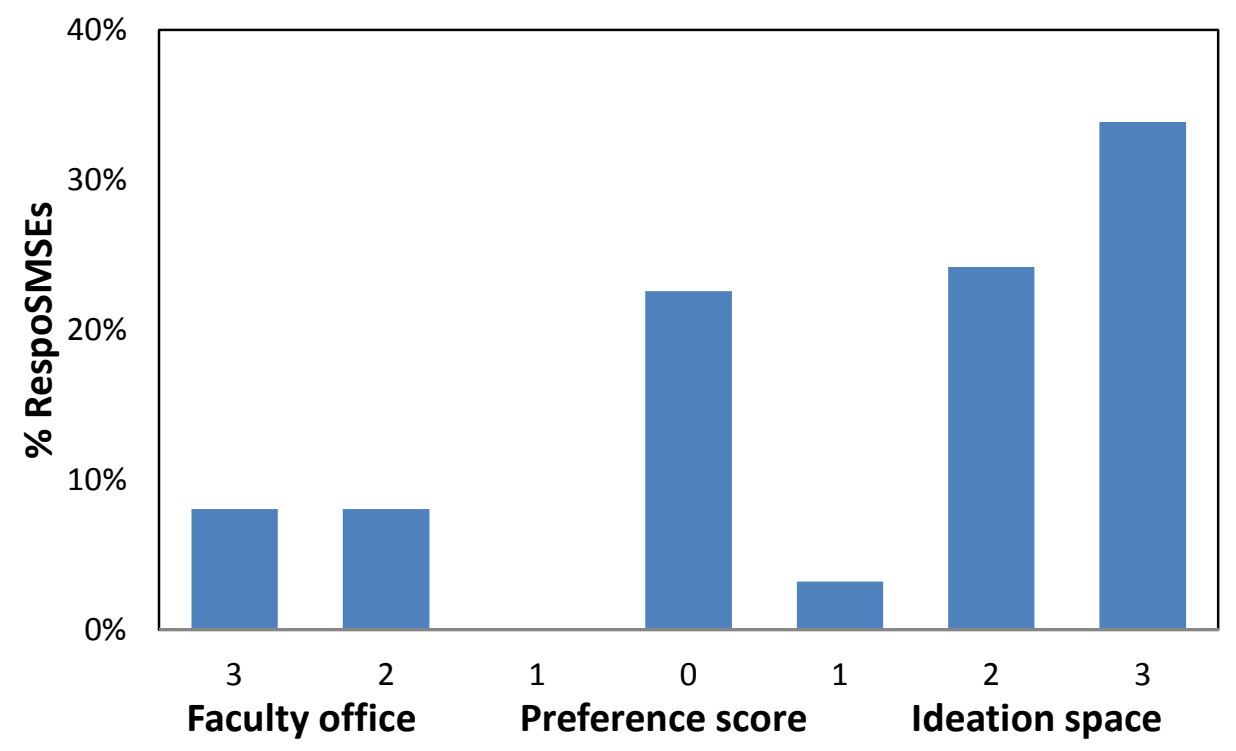

Figure 2 Student preferences in obtaining faculty help with examples.

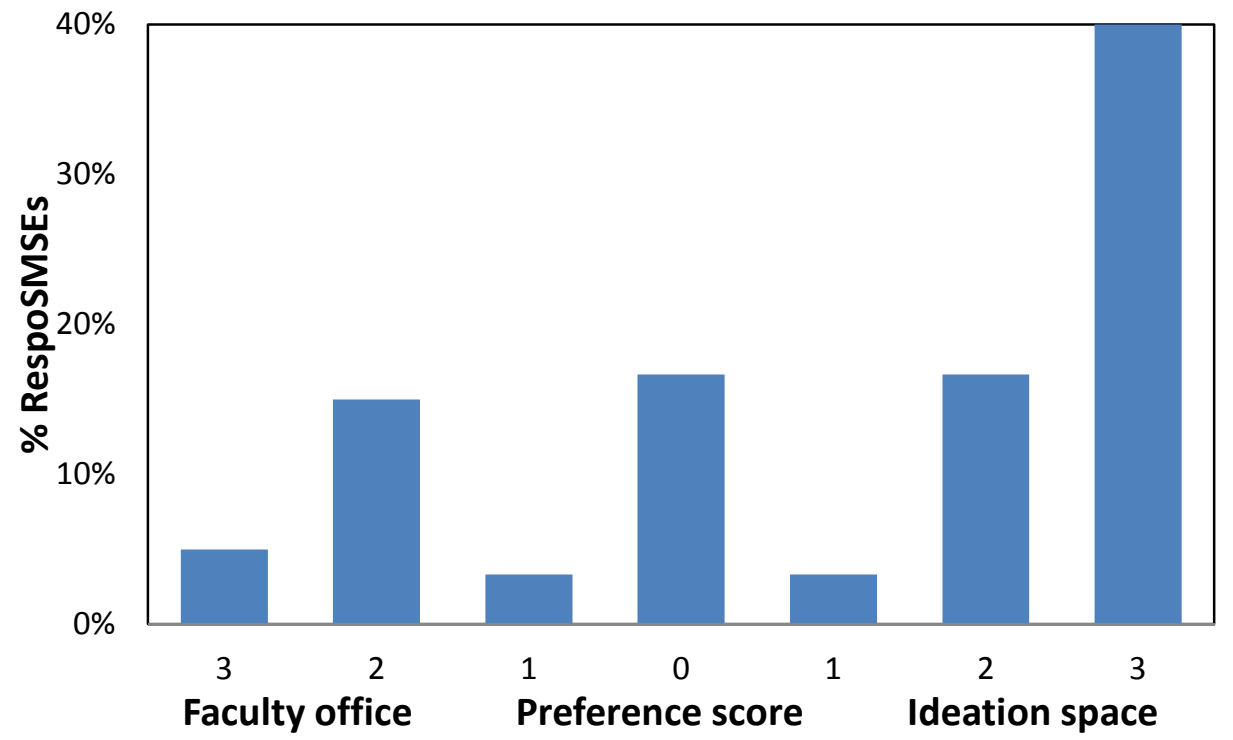

Figure 3 Student preferences in obtaining faculty help with exam preparation. 


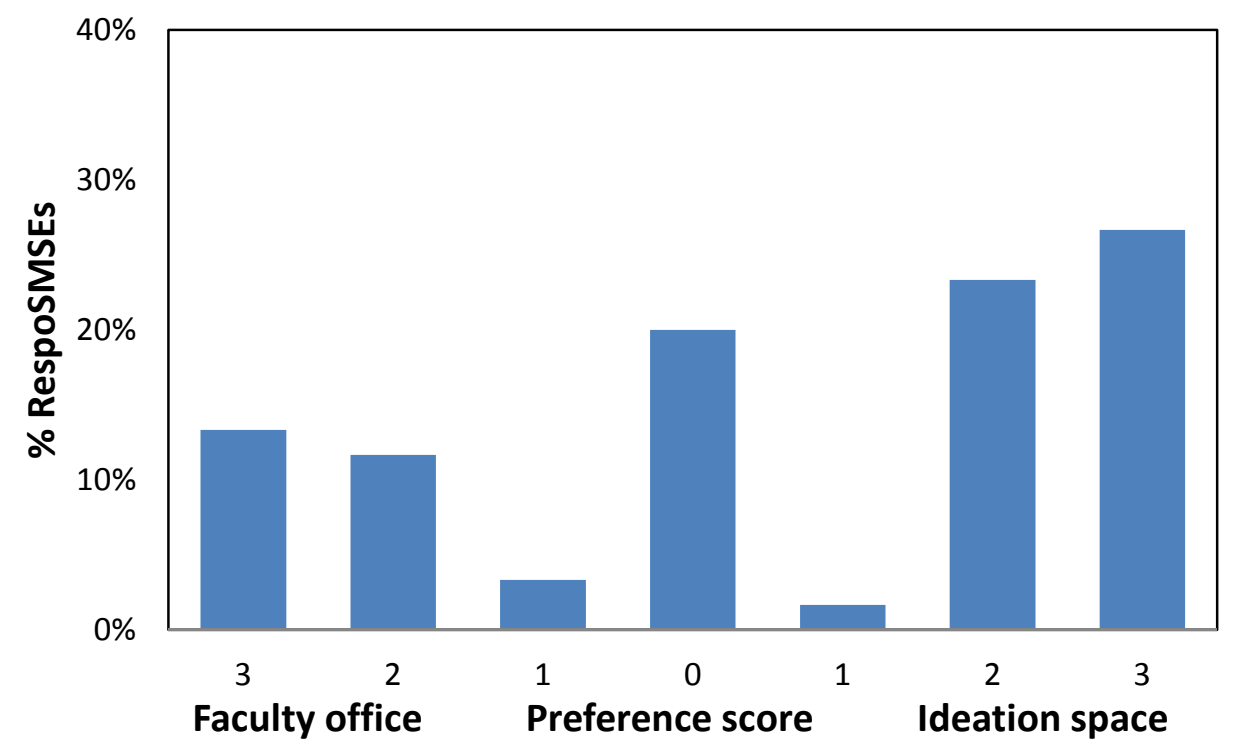

Figure 4 Student preferences in obtaining faculty help with homework.

Questions concerning the lecture produced inconclusive preferences among the students in the study with a very slight ( 0.13 steps) edge toward the faculty office (Figure 5 ). When dealing only with the smaller faculty offices, the results were similarly inconclusive, but edged toward the ideation space by 0.06 steps (a change of 0.19 steps).

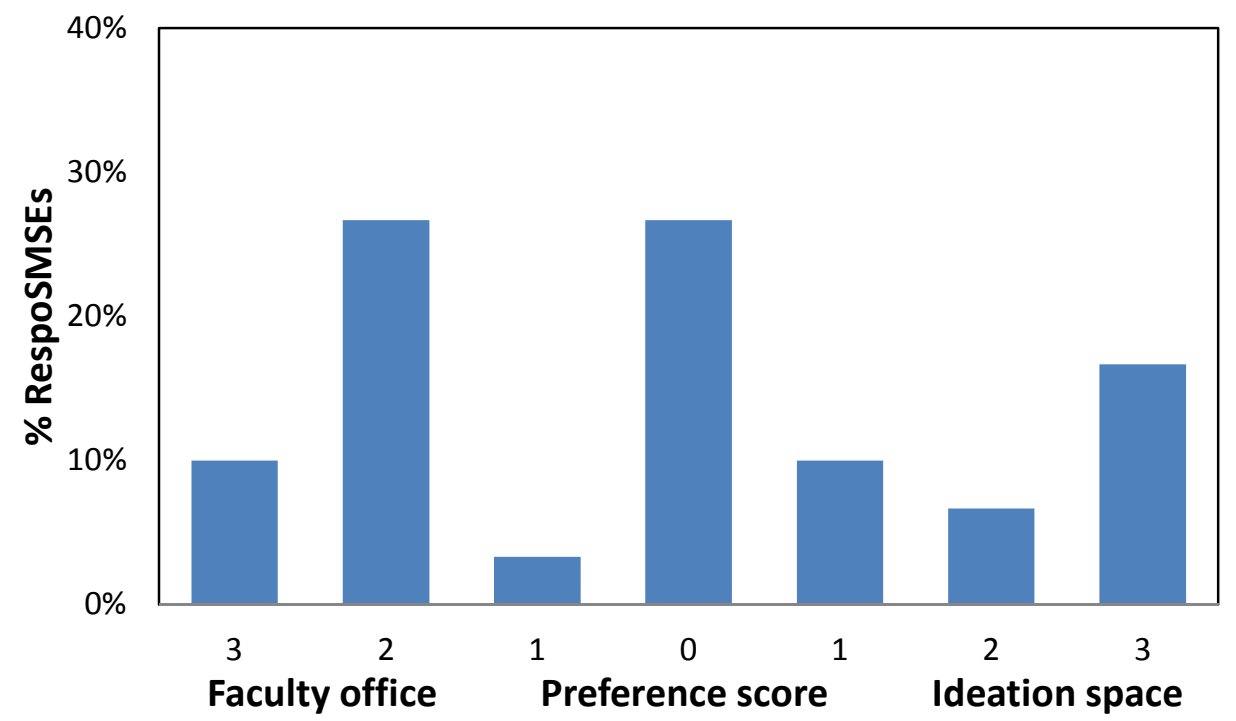

Figure 5 Student preferences in obtaining faculty help with questions from the lecture.

Distinctly different than all other questions, academic advising was overwhelmingly preferred (2.2 steps) to be in the faculty office (Figure 6). Student comments indicated that academic advising and personal issues require private space:

- "The ideation space seems ideal for $h w$ and questions due to the whiteboards and being open, but I'd prefer office hours to talk about advising because it seems more personal." 
- "the office is better for one-on-one questions about homework and question from lecture."

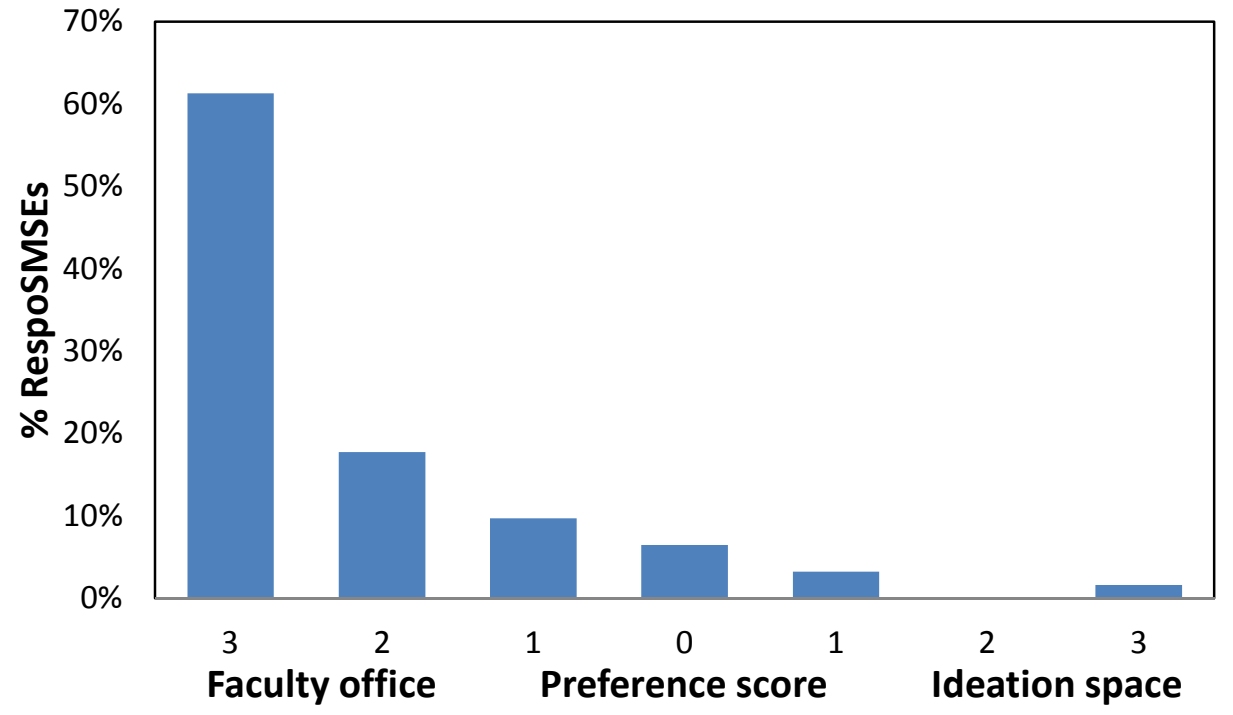

Figure 6 Student preferences in obtaining faculty help with academic advising.

\section{Summary and plans for the future}

A one-semester study comparing student preference for faculty office hours held in the faculty office to those in a large public (ideation) space was reported upon. Students participating in the study were enrolled in a broad spectrum of engineering courses ranging from introductory freshman course to senior engineering major-specific courses. Initial data analysis seems to indicate that holding a portion of traditional faculty office hours in a large, public space is a worthwhile endeavor. Many students showed a distinct preference for the SMSE ideation space: "I liked using the ideation space b/c there is more room to communicate with other students, as well as the professor." Other students had a positive perspective on both spaces: "I think both spaces were fine, but more individual in office and a lot of peer help as well as professor's help in ideation space."

Still, large spaces do have negative aspects: "I feel others are distracted if there are lots of students making noise in the ideation space"; "[the] office is quieter". One situation noticed by both faculty and students was the tendency for students to cluster around the professor creating a situation similar to a wall-less office: "I believe that when the office hours were done in the ideation space there was not enough time with the professor. Certain groups were always there and didn't allow everyone to get one-on-one time with the professor. I felt uncomfortable to ask questions with larger groups around and stopped coming to the hours because I felt there was no chance to ask questions needed." 
The SMSE faculty involved in this study plan to continue this study over at least another academic year. As the team's teaching assignments change the continuation study will extend over a broader range of students and courses. With an increased sample size, more detailed analysis of data will be undertaken.

\section{Acknowledgements}

This study was approved by the USD Institutional Review Board, project number 2015-12-077. The authors would like to thank the ASEE Educational Research and Methods Division reviewers for their extensive and helpful comments targeted not only on the paper itself, but also, most helpfully, on future research on this topic. The Ideation Space used in this study was made possible by a generous gift to SMSE from San Diego-based Cymer, Inc., makers of complex lasers used in semiconductor production. This study's faculty team greatly appreciates Cymer's generosity.

\section{Bibliography}

[1] M. Komarraju, S. Musulkin and G. Bhattacharya, "Role of student-faculty interactions in developing college students' academic self-concept, motivation, and achievement," Journal of college student development, vol. 51, no. 3, pp. 332-342, 2010.

[2] L. M. Martin, "the relatinship of college experiences to psychosocial outcomes in students," Journal of college student development, vol. 41, no. 3, pp. 292-301, 2000.

[3] C. A. Amenkhienan and L. R. Kogan, "Engineering students' perceptions of academic activities and support services: Factors that influence their academic performance," College student journal, vol. 38, no. 4, p. 523, 2004.

[4] M. K. Nadler and L. B. Nadler, "Out of class communication between faculty an students: a faculty perspective," Communication studies, vol. 51, no. 2, pp. 176-188, 2000.

[5] L. Li and J. P. Pitts, "Does it really matter? Using virtual office hours to enhance studentfaculty interaction," Journal of information systems education, vol. 20, no. 2, pp. 175-185, 2009.

[6] D. Graham and T. T. Bachmann, Ideation: The birth and beath of ideas, New York: John Wiley and Sons, Inc., 2004.

[7] S. Gopalakrishnan and F. Damanpour, "A review of innovation research in economics, sociology and technology management," Omega, vol. 25, no. 1, pp. 15-28, 1997.

[8] A. F. Osborn, Applied imagination: Principles and procedures of creative thinking, 3rd. ed., Charles Scribner's Sons, 1979.

[9] E. De Bono, Lateral thinking: Creativity step by step, Harper and Row, 1970.

[10] G. Pahl and W. Beitz, Engineering design: A systematic approach, 2nd. ed., London: Springer, 1996. 
[11] G. S. Altshuller, Creativity as an exact science, New York: Gordon and Breach, 1984.

[12] J. J. Shaha, S. M. Smith and N. Vargas-Hernandez, "Metrics for measuring ideation effectiveness," Design Studies, vol. 24, no. 2, pp. 111-134, March 2003. 